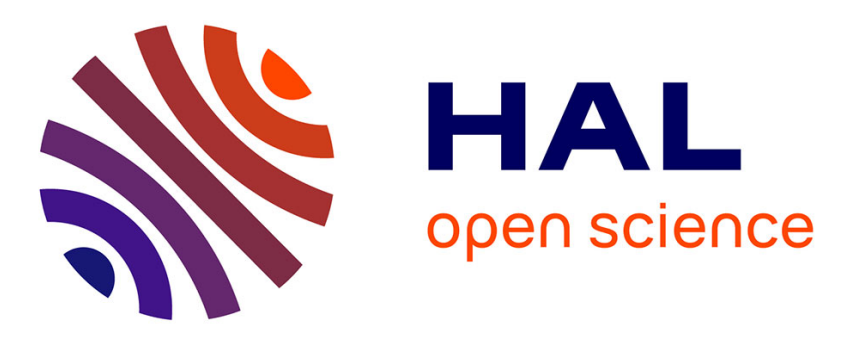

\title{
Modelling squared returns using a SETAR model with long-memory dynamics
}

Gilles Dufrénot, Dominique Guegan, Anne Peguin-Feissolle

\section{To cite this version:}

Gilles Dufrénot, Dominique Guegan, Anne Peguin-Feissolle. Modelling squared returns using a SETAR model with long-memory dynamics. Economics Letters, 2005, 86, pp.237-243. 10.1016/j.econlet.2004.07.014 . halshs-00179285

\section{HAL Id: halshs-00179285 \\ https://shs.hal.science/halshs-00179285}

Submitted on 15 Oct 2007

HAL is a multi-disciplinary open access archive for the deposit and dissemination of scientific research documents, whether they are published or not. The documents may come from teaching and research institutions in France or abroad, or from public or private research centers.
L'archive ouverte pluridisciplinaire HAL, est destinée au dépôt et à la diffusion de documents scientifiques de niveau recherche, publiés ou non, émanant des établissements d'enseignement et de recherche français ou étrangers, des laboratoires publics ou privés. 


\title{
Modelling squared returns using a SETAR model with long-memory dynamics ${ }^{* \dagger}$
}

\author{
Gilles DUFRENOT ${ }^{\ddagger}$ Dominique GUEGAN ${ }^{\S}$ \\ Anne PEGUIN-FEISSOLLE
}

July 7, 2004

\begin{abstract}
This paper presents a 2-regime SETAR model for the volatility with a long-memory process in the first regime and a short-memory process in the second regime. Persistence properties are studied and estimation methods are proposed. Such a process is applied to stock indices and individual asset prices.
\end{abstract}

Keywords: SETAR - Long-memory - FARIMA models - Stock indices.

JEL classification: C32, C51, G12

\footnotetext{
* Corresponding author: Anne PEGUIN-FEISSOLLE, GREQAM, Centre de la Vieille Charité, 2 rue de la Charité, 13002 Marseille, France, tel: +33.4.91.14.07.35, fax: +33.4 .91 .90 .02 .27 , Email: peguin@ehess.univ-mrs.fr

${ }^{\dagger}$ A first version of this paper was presented at the International Conference on Forecasting Financial Markets, Paris, June 2003, and at the International Workshop "Models with breaks in Economics and Finance: Recent Developments", Paris, November 2003. We gratefully acknowledge the comments from the participants to these conferences. We also thank the Conseil Régional of PACA for financial support and Aldric Pouron for providing us with the data. Helpful comments and suggestions from a referee and the editor are also gratefully acknowledged.

${ }^{\ddagger}$ ERUDITE, Université Paris 12 and GREQAM, France

${ }^{\S}$ Ecole Normale Supérieure de Cachan, MORA-IDHE, France

ฯ GREQAM-CNRS, France
} 


\section{Introduction}

It is common wisdom that asymmetric volatility is a characteristic of financial markets. The asymmetric dynamics takes different forms: regimes of high and low volatilities vary both in size and duration according to market microstructures, the price-volume relationships varies with economic expansions and recessions variables, etc.. A variety of alternative models has been proposed in the literature to account for this phenomena. In this paper, we propose to describe the regimes of the volatility of returns using a SETAR model with one regime characterized by a long-memory dynamics and the other by weak dependence:

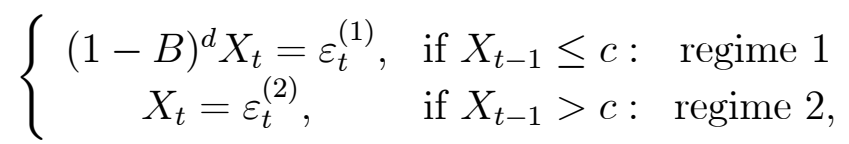

or

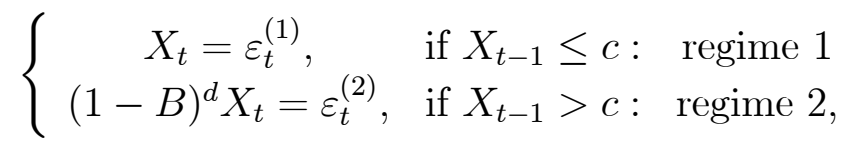

where $d \in(0,1 / 2)$ is a fractional difference parameter, $\varepsilon_{t}^{(i)}, i=1,2$ are strong white noises with finite variances, $B$ is the backward shift operator. This model relies upon three series of arguments put forward in previous papers of the literature.

The first point is that SETAR-type models can be more convenient than standard GARCH family models to describe volatility clustering in stock returns, if the volatility series exhibit different serial autocorrelation orders when the volatility is large and when it is small (see, among others, Cao and Tsay (1992), Li and Li (1996), Brooks (2001)). Usually, it is assumed that, in all the regimes, the volatility process is driven by short-memory AR models. In using our SETAR process, we introduce a persistence dynamics in at least one regime.

The second point concerns the separation between the two regimes. Some authors in the literature have argued that the persistence of volatility depends upon the size of the shocks (see, for instance, Friedman and Laibson (1989) and Schwert (1990). Since, in general, large shocks imply a higher risk on the assets than ordinary shocks, our regimes in equation (1) refer to a "high risk regime" and "low risk regime". Equation (2) illustrates another situation. Pockets of predictability may exist when high volatility is observed and the long-memory process captures clustering dynamics in high volatilities. Our model can be viewed as an alternative approach to the literature based on 
multiple factors models of volatility such as in Gallant, Hsu and Tauchen (1999); these authors indeed proposed a three factor model that mimics the long-memory behavior of financial volatility.

Thirdly, how to model the persistence of volatility is still an open question in the literature. Engle and Lee (1999) propose a decomposition of a GARCH $(2,2)$ model into permanent and transitory components. Andersen et al. (2003) suggest an approach based on realized volatility series applied to long-memory Gaussian processes and obtain better forecasts in comparison with more standard ARCH processes. In the recent years, some authors have suggested the combination of nonlinear and long-memory models; our paper can be seen as a further contribution in this sense (see, Franses and Paap (2002), Franses, Van der Leij and Paap (2002), van Dijk, Franses and Paap (2002), Guégan (2000, 2003)).

The paper is organized as follows. In section 2, we briefly introduce the properties of the model and propose simple methods to locate the parameter c. Section 3 adapts the model to three series of returns and a comparison with ARFIMA models is made using Diebold and Mariano (1995)'s forecastibility criterion. Section 4 concludes.

\section{The properties of the model and methods to locate the threshold parameter}

Regime 1 in model (1) is referred as the "long-memory" regime in Granger (1980)'s sense. We say that a stationary process $\left(X_{t}\right)_{t}$, whose autocovariance function is $\gamma_{X}$, is long memory if, $\forall t$ and $\forall \tau$,

$$
\gamma_{X}(\tau) \sim C(d) \tau^{2 d-1}, \text { as } \tau \rightarrow \infty
$$

where $0<d<1 / 2$ and $C(d)$ is a constant which depends only on $d$. Under the assumption that $\varepsilon_{t}^{(i)}, i=1,2$ are strong white noises with finite variances, model (1) is both locally (in each regime) and globally stationary and invertible. Its autocorrelation function, $\gamma_{X}(\tau)$, can be written as:

$$
\gamma_{X}(\tau)=C(\tau, d) N_{1}(c)+\gamma_{\varepsilon}(0) N_{2}(c),
$$

where

$$
C(\tau, d)=\frac{\Gamma(1-2 d) \Gamma(\tau+d)}{\Gamma(d) \Gamma(1-d) \Gamma(\tau+1-d)} .
$$

$N_{1}(c)$ and $N_{2}(c)$ are the percentages of observations, respectively in regime 1 and in regime 2 and depend upon the threshold $c . \gamma_{\varepsilon}(0)$ is the variance of the 
noise $\left(\varepsilon_{t}^{(2)}\right)_{t}$. The theoretical autocorrelation function is thus a mixture of the autocorrelation of the long-memory model in regime 1 and of the variance of the white noise model in regime 2.

Even in a simple formulation such as ours, the estimation of the model parameters $(d, c)$ is substantially more difficult than in the cases of ARFIMA models or standard SETAR models. Ideally, one would like to apply here methods based on maximum likelihood approach (the Whittle estimator), but this is not feasible because the model is piecewise linear. Further, it is not possible to apply the variety of methods suggested for standard SETAR models because of the presence of the fractional parameter in one regime. The approach we adopt here is as follows.

- One estimates the value of the threshold parameter c.

- The observations are separated into two sub-groups according to the estimated value of $c$ and one deduces $N_{1}(c), N_{2}(c)$.

- Classical methods are applied to each sub-group to obtain an estimation of the fractional parameter (GPH, non-parametric methods, Whittle). If the model (1) is adequate to describe the data, then one must find a significant parameter $d$ for one sub-group and a non significant parameter for the other sub-group.

The crucial point concerns step 1 where the parameter $c$ has to be locate We first construct the time series $\left(\widetilde{X}_{t}\right)_{t}$ of arranged observations according to the decreasing values of $X_{t-1}$ and then proceed as follows:

1. One considers a set of $s_{1}$ initial observations of $\left(\widetilde{X}_{t}\right)_{t}$ and estimate the long-memory parameter and the corresponding $t-$ ratio: $t_{s_{1}}$.

2. The vector $\left(\widetilde{X}_{t}\right)_{t}$ is then incremented in such a way to contain $s_{2}, s_{3}$, $\ldots, s_{n}$ observations; new long-memory parameters and their $t$-ratios are computed: $t_{s_{2}}, t_{s_{3}}, \ldots, t_{s_{n}}$.

3. Consider the set of estimated t-ratios $\left\{t_{s_{1}}, t_{s_{2}}, t_{s_{3}}, \ldots, t_{s_{n}}\right\}$. One tests for the presence of a structural break $\widetilde{t}$ in the view of finding a sequence of t-ratios such that, for instance, for $t_{s_{k}} \leq \widetilde{t}$, the estimated long-memory parameters are not statistically significant, while, for $t_{s_{k}}>\widetilde{t}$, they are significant.

A simple way to do this is to use a standard Chow test. The series of tratios is regressed on a linear time trend, using incremented dummy variables: 
for $k=1,2, \ldots, n$

$$
t_{s_{k_{t}}}=\left(\alpha+\beta D_{t}\right)+\left(\gamma+\delta D_{t}\right) t+u_{t},
$$

where $u_{t}$ is a strong white noise and

$$
D_{t}=\left\{\begin{array}{l}
1, \quad \text { if } t \leq \widetilde{t} \\
0, \quad \text { otherwise }
\end{array}\right.
$$

We test the null hypothesis $H_{0}: \beta=\delta=0$ against the alternative $H_{1}: \beta \neq 0$ or $\delta \neq 0$. The test is implemented by considering different values of $\widetilde{t}$ and finally one retains the value yielding the lowest $\mathrm{p}$-value. Instead of using the Chow test, one can also compute the sum of squares residuals corresponding to the equation and select the $t$-ratio (and thus the threshold value) yielding the lowest sum (see Dufrénot, Guégan and Péguin-Feissolle (2003)).

\section{Empirical application}

In this section we apply the model to two individual assets (ST-GOBAIN and TOTAL) and a stock index (FTSE) using daily data over the period 1998-2003. We consider the squared absolute returns

$$
X_{t}=\left|\log \left(p_{t}\right)-\log \left(p_{t-1}\right)\right|^{2},
$$

where $p_{t}$ is the price index at time t. Table 1 shows our results. The data successfully detect the presence of two distinct regimes in the volatility of the three stock indices. To save place, we report the results for which the change point in the t-ratios is obtained using the Chow-based method (the approach based on the minimum sum of squares yields similar results). Further, we report the estimations of the fractional parameters based on the GPH method: $\widehat{d}$ corresponds to a simple ARFIMA model on the whole series, and $\widehat{d}_{1}$ and $\widehat{d}_{2}$ to the fractional parameters of both regimes in model (1) or $(2)$; $\widehat{c}$ is the value of the threshold parameter, $N_{1}$ and $N_{2}$ are the number of points in the regimes and the last row gives the corresponding model (1) or (2).

Several comments are in order.

- Firstly, comparing the t-ratios of the fractional parameter in the two regimes, we find evidence that both the models (1) and (2) are able to capture the state-dependent dynamics of the volatility. For instance, in the case of ST-GOBAIN, the low volatility regime is characterized by some predictable slow dynamic adjusting behavior, whereas for TOTAL the volatility is highly persistent in the regime of large past volatility. 
- A second point is that, for these two indices, we approximately have the same number of observations within each regimes. The implications for market analysts is that strategies based on technical analysis (charts, market timing, dynamic asset allocation) and those based on investment strategies (for instance, portfolio insurance) are not mutually exclusive. The former can be used when a persistent volatility generating process is detected and the latter during the periods of unpredictable volatilities.

- A third interesting point concerns the difference between an aggregate stock index like FTSE and disaggregated firms' stock indices. Although we find a two-regime model for the FTSE index, it is seen that the number of points in the white noise regime is only approximately $10 \%$ of the sample. The upshot of our result is that we might expect our model to apply to the volatility of the firms' assets rather than to aggregate indices. One reason can be that our "on/off" persistent volatility model captures the influence of market microstructures that would not be found when individual assets are aggregated.

Finally, it is interesting to enquire as to whether a model where the persistence of the volatility is allowed in one regime only produces forecasts that are superior to a one-regime long-memory model. Table 2 reports some results of predictive accuracy based on Diebold and Mariano (1995)'s test statistics. The number in bold correspond to cases where the SETAR model yields forecasts that are statistically different from those obtained with a ARFIMA model. The number $n$ in the table indicates the percentages of points for which the residuals of our model are inferior to those of the oneregime ARFIMA model. As is seen, the numbers are higher than $50 \%$, which suggests that our model offers an alternative competing framework to describe the persistence of the volatility.

\section{Conclusion}

This paper has proposed a new model to investigate the long-memory dynamics of volatility that contains a mixture of long-memory and white noise structures. Other further research topics are the following. Firstly, one can conjecture that the model suggested here can be extended to the case where regime 1 is described by an ARFIMA model and regime 2 by a stationary $A R M A$ model or by a mixing process. Secondly, the model can be applied to time series other than returns; for instance, it seems worthwhile to investigate the case corresponding to $\left|\log \left(p_{t}\right)-\log \left(p_{t-1}\right)\right|^{4}$ : it is a way to 
measure the kurtosis of its underlying distribution. Thirdly, the SETAR model with long-memory behavior can be studied under the assumption of heteroskedastic errors in order to incorporate the influence of volatility of the long-memory structure. Finally, it would be interesting to apply our model to realized volatility, using for instance price-range as in Alizadeh et al. (2002), and compare its performance with other models developed in the literature. 


\section{References}

[1] Alizadeh, S., M. Brandt and F. Diebold, 2002, Range-based estimation of stochastic volatility models, Journal of Finance 57, 3, 1047-1091.

[2] Andersen, T.G., J. Bollerslev, F.X. Diebold and P. Labys, 2003, Modelling and forecasting realized volatility, Econometrica 71, 579-625.

[3] Brooks, C., 2001, A double-threshold GARCH model for the Franc/Deutschemark exchange rate, Journal of Forecasting 20, 135-140.

[4] Cao, C.Q. and R.S. Tsay, 1992, Nonlinear time series analysis of stock volatilities, Journal of Applied Econometrics 7, 165-185.

[5] Diebold, F.X. and R. Mariano, 1995, Comparing predictive accuracy, Journal of Business and Economic Statistics, 253-263.

[6] Dufrénot, G., D. Guégan and A. Péguin-Feissolle, 2003, A SETAR model with long-memory property, International Conference on Forecasting Financial Markets, Paris, June.

[7] Engle, R. and G.G. Lee, 1999, A permanent and transitory model of stock returns volatility, in: R. Engle and H. White, eds., Cointegration, causality an forecasting: a Festchrift in honor of Clive W.J. Granger, 475-497 (Oxford University Press).

[8] Franses, P.H. and R. Paap, 2002, Censored latent effects autoregression, with an application to US unemployment, Journal of Applied Econometrics 17, 347-366.

[9] Franses, P.H., M. van Der Leij and R. Paap, 2002, Modelling and forecasting level shifts in absolute returns, Journal of Applied Econometrics 17, 601-616.

[10] Friedman, B. and D.I. Laibson, 1989, Economic implications of extraordinary movements in stock prices, Brookings papers on Economic Activity $2,137-189$.

[11] Gallant, H.R., C. Hsu and G. Tauchen, 1999, Using the daily range data to calibrate volatility diffusions and extract the forward integrated variance, Review of Economics and Statistics, 81, 4, 617-631.

[12] Granger, C.W.J., 1980, Long memory relationships and the aggregation of dynamic models, Journal of Econometrics 14, 227 - 238. 
[13] Guégan, D., 2000, A new model: the $k$-Factor GIGARCH Process, Journal of Signal Processing 4, 265 - 271.

[14] Guégan, D., 2003, A Prospective study of the $k$-Factor Gegenbauer Processes with heteroscedastic errors and an application to inflation rates, Finance India, XVII, 165-197.

[15] Li, C.W. and W.K. Li, 1996, On a double threshold autoregressive heteroskedastic time series models, Journal of Applied Econometrics 11, 253-274.

[16] Schwert, G., 1990, Stock volatility and the crash of 87, Review of Financial Studies 3, 77-102.

[17] van Dijk, D., P.H. Franses and R. Paap, 2002, A nonlinear long-memory model with an application to US unemployment, Journal of Econometrics 110, 135-165. 
Table 1. Parameter estimates for absolute squared returns

\begin{tabular}{cccc}
\hline & ST GOBAIN & TOTAL & FTSE \\
\hline \hline$\widehat{d}$ & 0.0919 & 0.1066 & 0.3165 \\
t-ratio & $(3.09)$ & $(2.51)$ & $(8.90)$ \\
$\widehat{c}$ & 0.0001 & 0.0002 & 0.0006 \\
$N_{1}$ & 606 & 740 & 1236 \\
$\widehat{d}_{1}$ & 0.0904 & 0.0560 & 0.2907 \\
t-ratio & $(3.29)$ & $(1.37)$ & $(6.90)$ \\
$N_{2}$ & 734 & 600 & 102 \\
$\widehat{d}_{2}$ & 0.1064 & 0.1615 & 0.1835 \\
t-ratio & $(1.93)$ & $(3.06)$ & $(1.49)$ \\
Model & $(1)$ & $(2)$ & $(1)$ \\
\hline
\end{tabular}

Note:The change point in the t-ratios was obtained using the method based on the Chow test. $\widehat{d}_{1}$ and $\widehat{d}_{2}$ refer to the estimated fractional parameter, respectively in regime 1 and regime 2. $\widehat{d}$ is the estimated fractional parameter on the whole series. The t-ratio must be compared 1.96 (corresponding to the critical value at the $5 \%$ level of significance). A non- significant parameter indicates that the volatility is driven by a white noise process (and is thus unpredictable). Conversely, a significant parameter means that the volatility exhibit a long-memory dynamics therefore yielding to a high predictability. The last row shows the corresponding adequate model (1) or (2) 
Table 2. Test of predictive accuracy: our model versus an ARFIMA model ( $\mathrm{p}$-values)

\begin{tabular}{lrrrrrrc}
\hline & \multicolumn{1}{c}{ AS } & \multicolumn{1}{c}{ SI } & \multicolumn{1}{c}{ WI } & \multicolumn{1}{c}{ NB } & \multicolumn{1}{c}{ MGN } & MR & $\mathrm{n}$ \\
\hline \hline STGOBAIN & $\mathbf{0 . 0 6 7}$ & $\mathbf{0 . 0 0 0}$ & 0.403 & 0.155 & 0.310 & 0.113 & $55.19 \%$ \\
TOTAL & $\mathbf{0 . 0 0 0}$ & 0.396 & 0.232 & $\mathbf{0 . 0 4 1}$ & $\mathbf{0 . 0 8 2}$ & 0.113 & $51.16 \%$ \\
FTSE & 0.488 & $\mathbf{0 . 0 0 0}$ & $\mathbf{0 . 0 0 9}$ & 0.199 & 0.391 & 0.250 & $55.57 \%$ \\
\hline
\end{tabular}

Note: The different columns are: AS: Asymptotic test, SI: Sign test, WI: Wilcoxon's test, NB: Naive benchmark test, MGN: Morgan-Granger-Newbold's test, MR: MeeseRogoff's test, n: number of times in percent where the residuals coming from the TAR model with a long memory regime are smaller than the residuals coming from a standard long memory model (when $\mathrm{n}>50 \%$, it means that the TAR model seems the best). The null hypothesis is the hypothesis of equal accuracy of different predictive methods. The loss function is quadratic. The test statistics follows asymptotically different distributions: $N(0,1)$ for the asymptotic test, the sign test, the Wilcoxon's test, the Meese-Rogoff's test, $F\left(T_{0}, T_{0}\right)$ for the Naive benchmark test and a $t_{T_{0}-1}$ for the Morgan-Granger-Newbold's test (where $T_{0}$ is the number of predicted observations, i.e. $T_{0}=20$ ). The Meese-Rogoff test statistic is computed with the Diebold-Rudebusch covariance matrix estimator. The truncation lag is 10 for the asymptotic test and is given by the integer part of $T_{0}^{4 / 5}$ for the Meese-Rogoff's test. 